\title{
Catastrophic die-off of globally threatened Arabian Oryx and Sand Gazelle in the fenced protected area of the arid central Saudi Arabia
}

\author{
M. Zafar-ul Islam ${ }^{1,2}$, Khairi Ismail ${ }^{1,2} \&$ Ahmed Boug $^{1,2}$ \\ ${ }^{1}$ National Wildlife Research Center, PO Box 1086, Taif, Saudi Arabia \\ ${ }^{2}$ Saudi Wildlife Commission, Riyadh, Saudi Arabia \\ Email: ${ }^{1}$ mzafarul.islam@gmail.com (corresponding author)
}

\begin{abstract}
A large number of die-off of globally threatened Arabian Oryx (Oryx leucoryx), and Arabian Sand Gazelle (Gazella subgutturosa marica) were recorded from 1999 to 2008 in fenced Mahazat as-Sayd Protected Area (PA) in western-central Saudi Arabia. Mortalities of animals have been recorded during summer months when the rainfall is negligible or insignificant. Deaths were due to starvation because of reduced availability, accessibility and quality of food plants in the area. In total, 560 oryx and 2815 sand gazelle deaths were recorded since the reintroduction projects began till the end of 2008. Mortalities of animals were higher in 1999-2001, 2006, 2007 and 2008. Grazing of oryx habitat depends on rainfall and animals move over great distances in response to rain. The fence around Mahazat as-Sayd PA prevents natural movements of animals, and artificially concentrates the ungulate populations into possibly unfavourable habitat. The sand gazelle is a highly gregarious and migratory species, moving long distances in search of good quality pastures. Populations of sand gazelle in Central Asia are also known to migrate over large distances, covering several hundred kilometers. It is therefore likely that by preventing natural movements of sand gazelles and oryx, fencing may have reinforced the effects of stressful conditions such as drought. To reduce the catastrophic effects, a Strategy and Action Plan was developed in August 2008 to manage oryx and gazelle within the reserve and with provision for food and water at the five camps in the reserve as emergency plan to minimize mortalities.
\end{abstract}

Keywords: Mass mortalities of ungulates, Migration of Arabian Oryx and Arabian Sand Gazelle, Fencing Protected Area, Arid region, Saudi Arabia

Date of publication (online): 26 February 2010 Date of publication (print): 26 February 2010 ISSN 0974-7907 (online) | 0974-7893 (print)

Editor: S. Sathyakumar

\section{Manuscript details:}

Ms \# 02174

Received 06 April 2009

Final received 12 December 2009

Finally accepted 13 December 2009

Citation: Islam, M.Z., K. Ismail \& A. Boug (2010) Catastrophic die-off of globally threatened Arabian Oryx and Sand Gazelle in the fenced protected area of the arid central Saudi Arabia. Journal of Threatened Taxa 2(2): 677-684.

Copyright: (C) M. Zafar-ul Islam, Khairi Ismail \& Ahmed Boug 2010. Creative Commons Attribution 3.0 Unported License. JoTT allows unrestricted use of this article in any medium for non-profit purposes, reproduction and distribution by providing adequate credit to the authors and the source of publication.

Author Details: See end of this article

Author Contribution: See end of this article

Acknowledgements: See end of this article

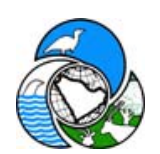

SWC, Riyadh

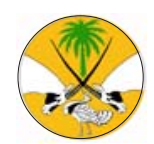

NWRC, Taif

\section{INTRODUCTION}

Many species of wild animals have distinct physiological and ecological advantages over traditional domesticated livestock species in arid and semi-arid areas. Amongst the most significant are an ability to thrive in the absence of surface water (by movement in time and space), to make optimal use of vegetative resources and their minimal impact on the environment. They also have disease-tolerant, heat-tolerant and droughttolerant attributes and their reproductive characteristics are more efficient (Islam et al. 2007).

However, placing wild animals in enclosed protected areas introduces a variety of new management issues, especially during times of drought and stress. These difficulties were witnessed firsthand during recent drought events that affected Mahazat as-Sayd Protected Area (PA) in Saudi Arabia. During several years and especially between 1999 and 2008, drought conditions have been a factor in mass mortalities of several threatened species (e.g., Arabian Oryx (Oryx leucoryx), Red-necked Ostrich (Struthio camelus camelus) and the Arabian Sand or Reem Gazelle (Gazella subgutturosa marica).

In this paper, we review the reintroduction of Sand Gazelle and Arabian Oryx in Mahazat as-Sayd PA, their present status, and the possible causes for large-scale mortalities in an enclosed area.

\section{STUDY SITE}

Mahazat as-Sayd PA (22 ${ }^{\circ} 15^{\prime} \mathrm{N} \& 41^{\circ} 40^{\prime} \mathrm{E}$ and elevation $\left.900-1,100 \mathrm{~m}\right)$ was declared in 1988 and ratified in 1989 by the Council of Ministers. It is located in Makkah province and encompasses an area of about $2200 \mathrm{~km}^{2}$ with fairly level, sandy plain (Image 1). In 1988 itself the fence was erected to protect the area from grazing. The substrate at Mahazat is sand, gravel, or alluvial clays, and is usually loose, but not shifting, forming an even surface. Mahazat as-Sayd is one of the world's largest fenced PAs. The entire $220 \mathrm{~km}$ perimeter is fenced with $2 \mathrm{~m}$ high chain-link fencing, topped with three strands of barbed wire, with $0.9 \mathrm{~m}$ of mesh buried in the ground, and lying behind a large earth embankment. Lying in central Saudi Arabia, Mahazat asSayd is a vast undulating plain. Protection from livestock grazing has allowed a spectacular recovery of native vegetation - the grasslands of the reserve are a reminder of what much of central Saudi Arabia must have once looked like. The vegetation recovery allowed the reintroduction of Arabian Oryx [Endangered], Sand Gazelles [Vulnerable], Houbara Bustard Chlamydotis macqueenii [Endangered] and Red-necked Ostrich. The reserve holds large natural populations of Red Fox Vulpes vulpes arabica 


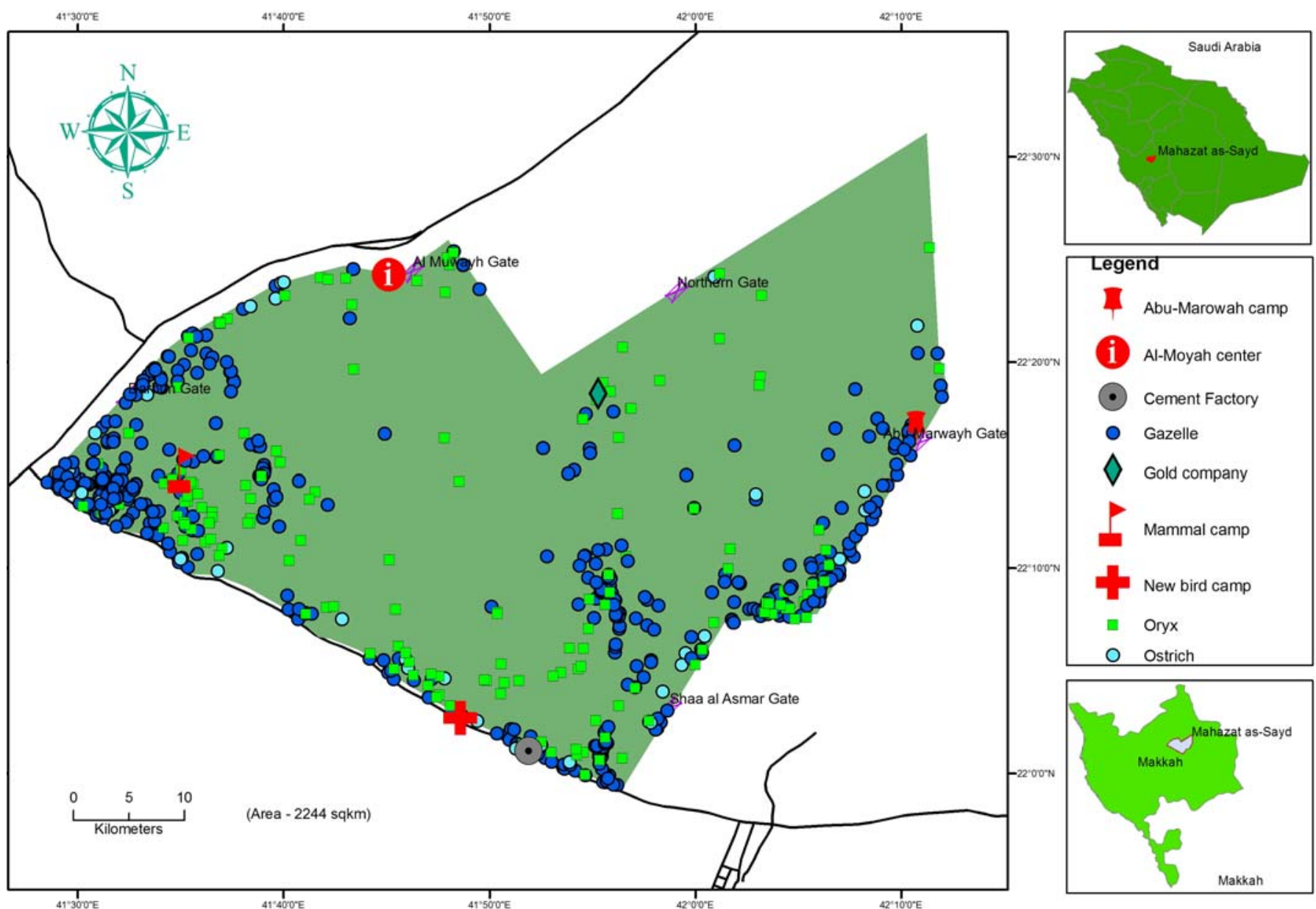

Image 1. Locations of carcasses of Arabian Oryx, Arabian Sand Gazelle and Ostrich in Mahazat as-Sayd Protected Area in Saudi Arabia during 2006, 2007 and 2008. (Most of the carcasses were recorded near the northwestern, southern and southeastern parts of the reserve mainly under green acacia or mearua trees, which were sites with typical thermal cover that are required for ungulates at Mahazat during summer months; while in the northeastern part very few carcasses were recorded which could be due to less vegetation in that section).

and Ruppell's Fox Vulpes rueppelli, significant numbers of Sand Cat Felis margarita, Wild Cat Felis silvestris and also Ratel Mellivora capensis but rarely sighted, and the Spinytailed Lizard Uromastyx sp. It is a major breeding area for the threatened Lappet-faced Vulture Torgos tracheliotus [Endangered] and an important stopover site for migrating birds (Islam et al. 2007). The Arabian Oryx was largely extinct in the wild by the early 1970s; reintroduction programmes have since been attempted, with mixed success since 1989 (Islam et al. 2007).

Climate and Weather conditions: Climate of the area is tropical and arid. Between 1991 and 2008, mean minimum and maximum temperatures measured ranged from $9^{\circ} \mathrm{C}$ and $42^{\circ} \mathrm{C}$, respectively (Fig. 1). During the same period, mean monthly humidity ranged from approximately 18 to $72 \%$. The weather data over the last 18 years shows considerable interannual variation in the amount (range $0-22 \mathrm{~mm}$ ) and timing of rainfall. Substantial rainfall typically occurs between March and May each year.

Since the weather data showed some missing values, a drought is defined as one year with extremely high temperatures and no or very little rain, or as two to three years in a row with very little rain. This has been shown to occur in Mahazat asSayd in about two out of 18 years, so the probability of a drought occurring is: $p$ (drought $)=0.125$

Rainfall: Rainfall has a strong influence on the presence or absence of annual plants, and is also the most important factor in production of grazing. Poor rainfall had a major detrimental impact on forage in the reserve in 2006-2008. Average rains recorded from 1991 to 2008 at Mahazat was $7.214 \mathrm{~mm}$ (Fig. 2). Very little rains were recorded in 2006; 2$3 \mathrm{~mm}$ in April 2007; while whole of 2008 was quite dry, but in November rainfall occurred in several areas with an average rainfall in November 2008 of $65.67 \mathrm{~mm}$, which was quite significant. After a month vegetation including grass species started growing and Acacia tortilis trees became green where the rainfall occurred. But the average rainfall in 2008 was $5.6 \mathrm{~mm}$.

Reintroduction of Sand gazelle: Sand Gazelle was historically distributed throughout Asia, from Palestine and the Arabian Peninsula to the Gobi Desert and northern China (Roberts 1977). According to the IUCN, the Sand Gazelle is classified as Vulnerable (Mallon 2008) and listed under Appendix II of the Convention on Migratory Species (CMS). There are two subspecies of Sand Gazelle, the one in the Arabian Peninsula excluding northern Iraq and Syria is G.s.marica and the one in the rest of Asia, northern Iraq, and Syria is G. s. subgutturosa (Harrison et al. 1991). Distribution 

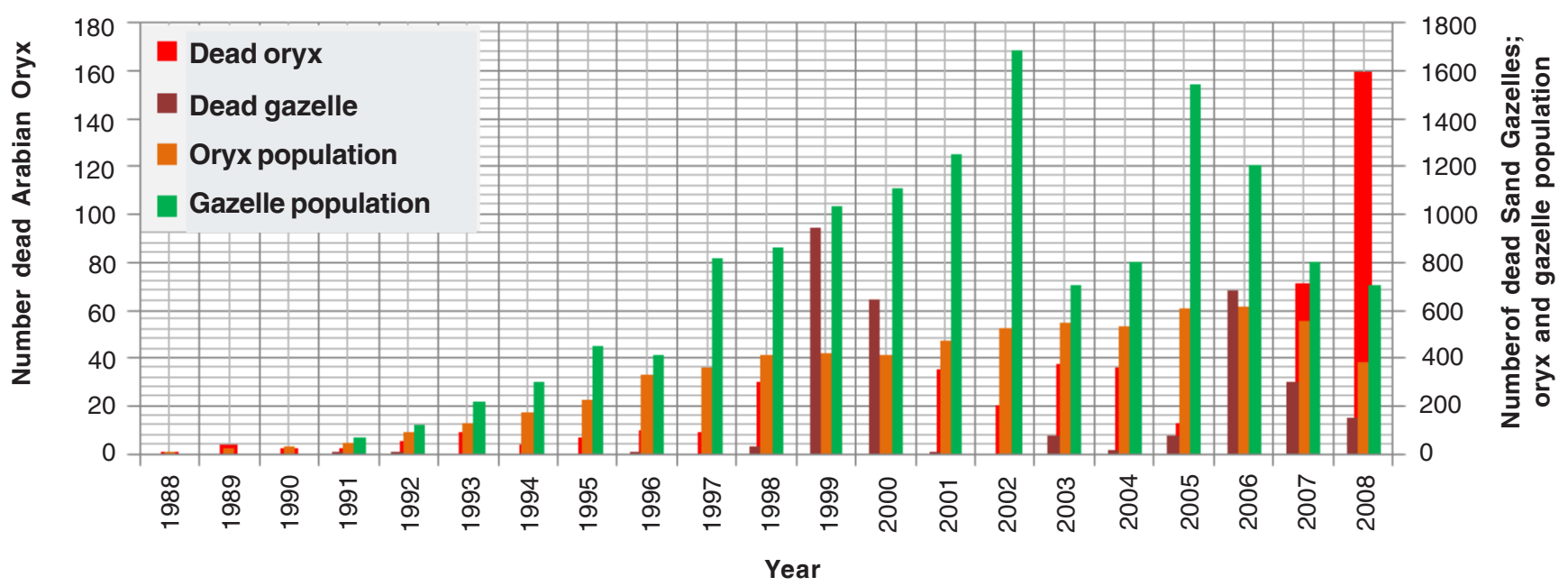

Figure 1. Mortalities and populations of Arabian Oryx and Sand Gazelle in Mahazat as-Sayd Protected Area, Saudi Arabia, 1988-2008.

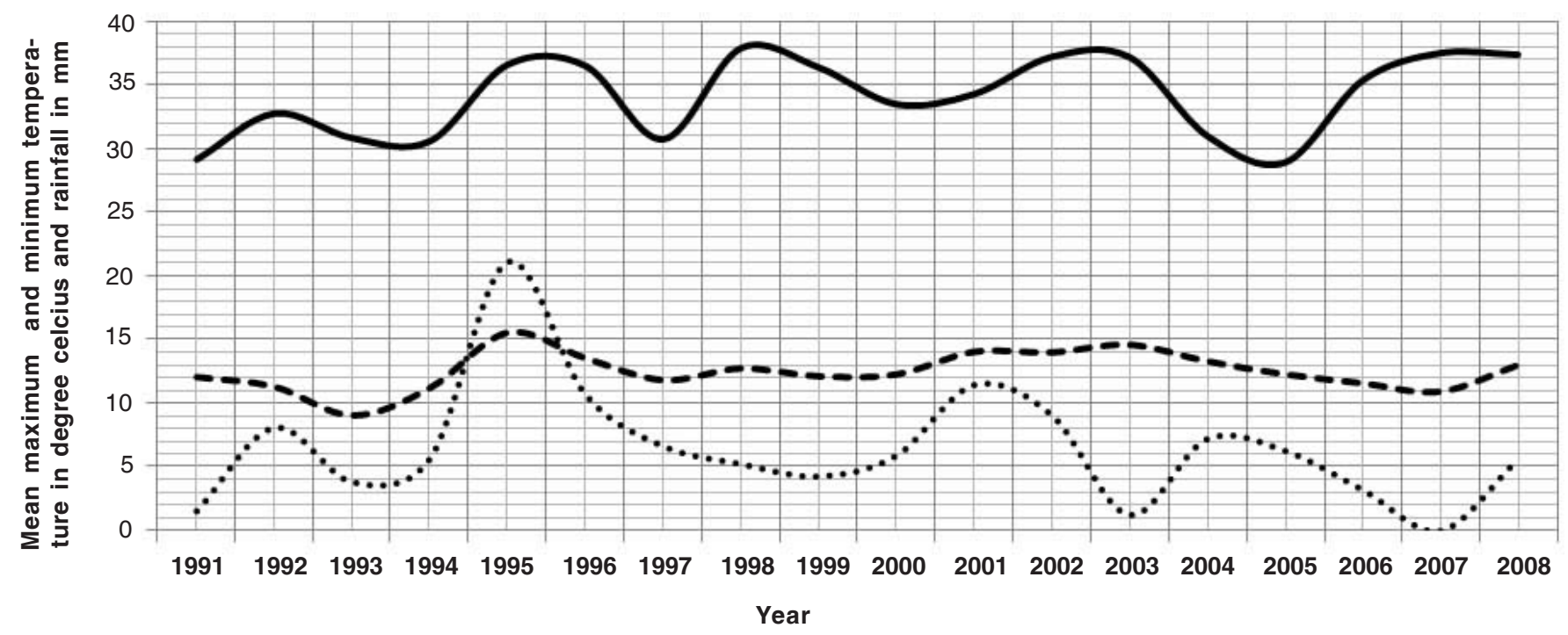

M. maximum temperature

M. minimum temperature

Mean rainfall in Mahazat

Figure 2. Mean maximum and minimum temperature and rainfall in $\mathrm{mm}$ from 1991 to 2008 in Mahazat as-Sayd Protected Area, Saudi Arabia.

of G.subgutturosa marica was almost in all parts of the Arabian Peninsula including the central Rub al Khali Desert (Philby 1933; Thesiger 1994) and even viewed as abundant in northern Saudi Arabia. Sand Gazelles are now confined to a few PAs mainly as reintroduced populations.

The reintroduction of Sand Gazelle was initiated in May 1991 when 98 captive-born gazelles (38 males and 60 females), from King Khalid Wildlife Research Center near Riyadh (Saudi Arabia's capital) and the Al-Sudairy gazelle collection at Qassim, and 66 of their offsprings (29 males and 37 females) were released into Mahazat as-Sayd PA (Asmode 1990; Haque \& Smith 1993). Before release, all the individuals were vaccinated against rabies, foot-and-mouth disease, rinderpest and pasteurellosis. They were kept in quarantine for three months before releasing them and hay, pellets and drinking water were provided. The present population of Sand Gazelle in Mahazat is 654 (Islam et al. 2008).

Reintroduction of Arabian Oryx: The Arabian Oryx was once widespread throughout Arabia from Syria to the Rub al Khali (southern part of Saudi Arabia). It was declared extinct in the wild in 1972 when the last specimen was shot in Oman. Previously in 1962-63 the Fauna and Flora Preservation Society captured three specimens ( 2 males \& 1 female) in Yemen. These three animals were sent to the Phoenix Zoo, USA and later to the San Diego Zoo, USA. To these specimens were added one female from Kuwait and four animals given by HRM King Saud. These eight animals constituted the founders of what was called "The World Herd". The World Herd was very successful and in December 1981 there were ca. 130 individuals, and now the population of Arabian Oryx in Saudi Arabia would be more than 1000 in the PAs.

In the mean time HRM King Khaled organized a herd on his farm at Thumama near Riyadh with animals from Saudi Arabia, Qatar and from the World Herd. Some of these animals were transferred in May 1986 to the NWRC. In six months NWRC registered seven births. The current populations in 


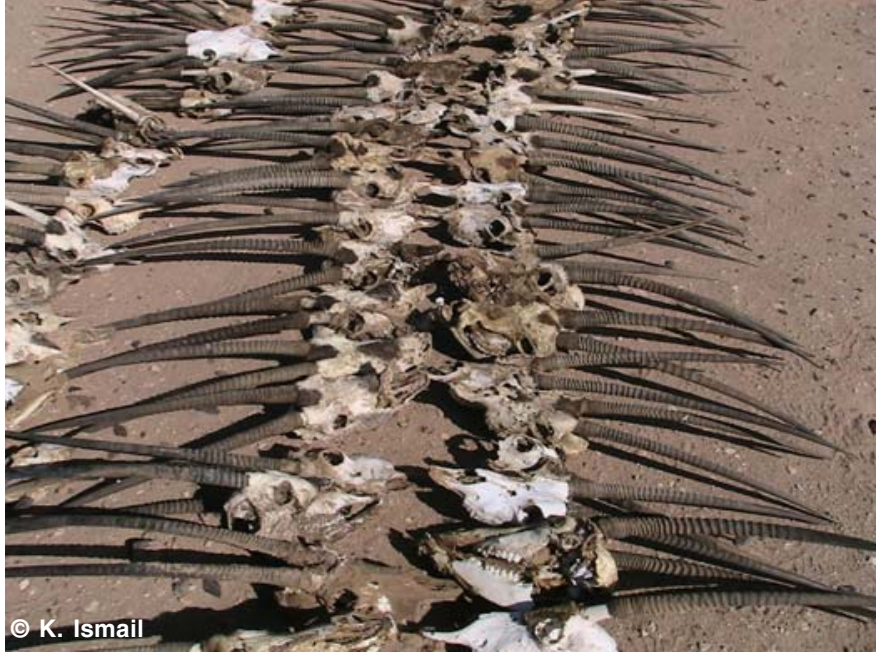

Image 2. Skulls of dead Arabian Oryx is systematically kept in one camp of Mahazat as-Sayd Protected Area.

Saudi Arabia are descendants of those animals.

Re-introduction programmes of Arabian Oryx were selected from the populations which were identical to the same species which had been exterminated as explained above. Founders were obtained from areas where the environment is as harsh as the reintroduction sites.

In Saudi Arabia, the Oryx conservation and restoration programme was initiated in 1989 by the National Wildlife Research Center (NWRC) under the Wildlife Conservation and Development (NCWCD). Concurrent conservation programmes for the protection of large areas within the former range of the Arabian Oryx, and the captive breeding of Oryx at the NWRC in Taif have together enabled the restoration of the species in the Kingdom: a first reintroduction took place in the fenced Mahazat as-Sayd PA in 1990 and in 1995 the second free-ranging population of Oryx in the world was established in the unfenced 'Uruq Bani Ma' arid PA in the "Empty Quarter" (southern part of Saudi Arabia).

Released animals were marked with suitable tags for identification and fitted with radio collars to enable them to be relocated after release. The post-release progress of Oryx has been carefully monitored and the information gained from early releases utilized in planning subsequent attempts were appropriate.

\section{Methods}

Ungulate surveys were carried out on a regular basis in the Mahazat as-Sayd PA since 1988, when 14 permanent transect lines were established in the area (Magin 1995). We used Distance sampling (Buckland et al. 1993) analysis techniques to generate estimates of the oryx and sand gazelle population sizes. In addition, a much cruder technique based on known births and deaths was also used since the first animals were reintroduced into the area (Islam et al. 2008).

Since 1989 whenever a carcass was located, skulls were collected after cutting and leaving the rest of the carcass at the same spot. All the skulls were kept systematically at the Mammal Camp in the Reserve (Image 2). This method was useful in avoiding re-counts and also provided minimal number of dead animals during the years particularly 1999 and 2006 to 2008 when a large number of mortalities of sand gazelle and oryx occurred.

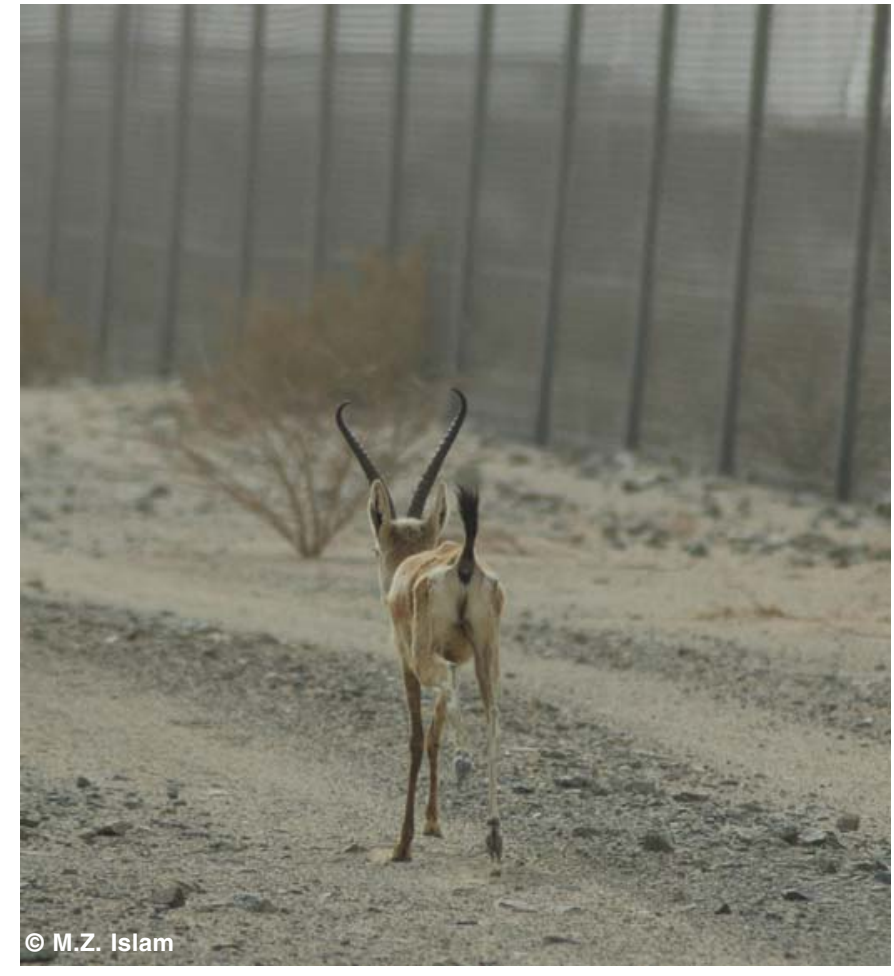

Image 3. A weak Arabian Gazelle about to die near the fence.

As most of the dead animals were found near the fence mainly under the Acacia and Maerua crassifolia trees, the distance from the fence to the location of dead animals was also measured. Regular monitoring of animals was carried out by vehicle and dead animals were located, GPS locations (coordinates), and vegetation around the carcass were recorded and each location was plotted on the map (Image 1).

Two key methods were adopted for monitoring the ungulates, and the details are as follows:

A sector-wise count to know the animal distribution in the Reserve, that was covered using the system of six sectors identified to both verify the status of the oryx and gazelle in the area and to collect data on the relative abundance of ungulates across the reserve.

Seddon et al. (2003) have indicated that the results obtained from the above technique was unsatisfactory as no marked gazelle were present within the area. The distance sampling technique was used to assess gazelle and oryx numbers (e.g., Seddon 1999).

\section{Results AND Discussion}

In general, mammals experience high initial mortality among young animals, followed by a phase in which mortality is low, but then increases. Population declines resulting from food shortages or poor habitat are characterised by an increase in mortality among young animals, which require more energy and water per body unit than adults to satisfy their high metabolic needs (Ostrowski \& Williams 2006). A similar mortality pattern was observed both in oryx and sand gazelles in Mahazat as-Sayd PA (Islam et al. 2007).

The mortality can be split into three categories, according to different groups of individuals in the ungulates population: female mortality (i) during pregnancy, (ii) shortly after giving birth, and (iii) due to old age; male mortality mainly caused by (i) injuries after fighting, and (ii) old age; calf mortality (the 
critical weeks and months at neonatal) (i) lack of adequate nutrients in the food, (ii) attacks by males (especially in a high population density), and (iii) heat during daytime.

For each group of mortality we have two different values, dependent on two weather conditions. A drought affects all three categories of mortalities. If there is a drought (not enough food), then mortality will be higher. If the weather conditions are good (enough food available), then mortality will be lower.

There are few detailed studies evaluating the impact of drought on wild ungulate mortality, however, in 1959-1960 in South Africa, all Sable Antelopes, $70 \%$ of Blue Wildebeest Connochaetes taurinus, $77 \%$ of Burchell's Zebra Equus quagga burchellii, 64\% of Impala Aepyceros melampus, $78 \%$ of Waterbuck Kobus ellipsiprymnus, $69 \%$ of Lesser Kudu Tragelaphus imberbis, and $71 \%$ of Southern Warthog Phacochoerus africanus sundevallii populations died in a mopaneveld area in the Northern Province (Bothma 1995). In view of these figures, the Arabian Oryx mortality in Mahazat as-Sayd in summer in the last several years is quite acceptable. Sand gazelle mortality appeared to be of similar amplitude $(50-60 \%)$ to that described for other ungulate species in South Africa.

The population of Arabian Sand Gazelle between 1991 to 2008 was estimated as $66,120,220,300,450,413,812,856$, $1034,1104,1245,1683,700,800,1537,1200,800$, and 654 based on distance sampling technique. From the population estimation exercise on 2 December 2008, the population size was 654 (95\% Cl 365 to 701 ), total number of observations 29, survey effort $326.4 \mathrm{~km}$ and mean group (cluster) size 19.41 (32.7\% cv).

The populations of Arabian Oryx from 1988 to 2008 was estimated as $9,19,31,42,89,128,170,221,326,355,405$, $415,413,469,523,547,529,605,614,550$ and 378 . On 2 December 2008, population size of Arabian Oryx was 378 (95\% Cl 113 to 432 ), total number of observations 47 , survey effort $231.1 \mathrm{~km}$ and mean group (cluster) size was 5.45 .

\section{Mortalities of sand gazelle}

During the stressful periods between 1991 and 2008, a large number of Arabian Sand Gazelles mortalities were recorded in Mahazat as-Sayd PA. Between these years, the number of dead Sand Gazelles were 13, 12, 3, 5, 0, 9, 0, 31, $939,644,8,0,77,21,77,679,302$ and 151 respectively (Ostrowsky \& Ismail 2000; Ismail 2005; Ismail \& Strauss 2006; Ismail 2007; Islam et al. 2007; Shah et al. 2008). Sand Gazelle are known to move long distances in search of more favourable areas during stressful conditions where food is available (Islam et al. 2007). The fenced reserve blocks the movement of the gazelle and they finally die near the fence (Image 3).

Most of the dead gazelles were found mainly under big green Acacia tortilis or Maerua crassifolia trees, which were typical shading places for ungulates at Mahazat during summer months. Then more dead gazelles were found in the vicinity of the external Mahazat as-Sayd fence especially southern and northwestern parts of Mahazat as-Sayd.

\section{Mortalities of Arabian Oryx}

The mortalities of Arabian Oryx were also recorded since the reintroduction and a large number of die-offs were recorded between 1998 to 2008 in Mahazat reserve, which were 30, 34, $26,35,20,37,36,12,46,71$, and 159. Most of the dead animals were mainly calves and lactating females. Very few calves of gazelles and oryx would have been predated by Red Fox or Ruppelles Fox. The data collection on the predation

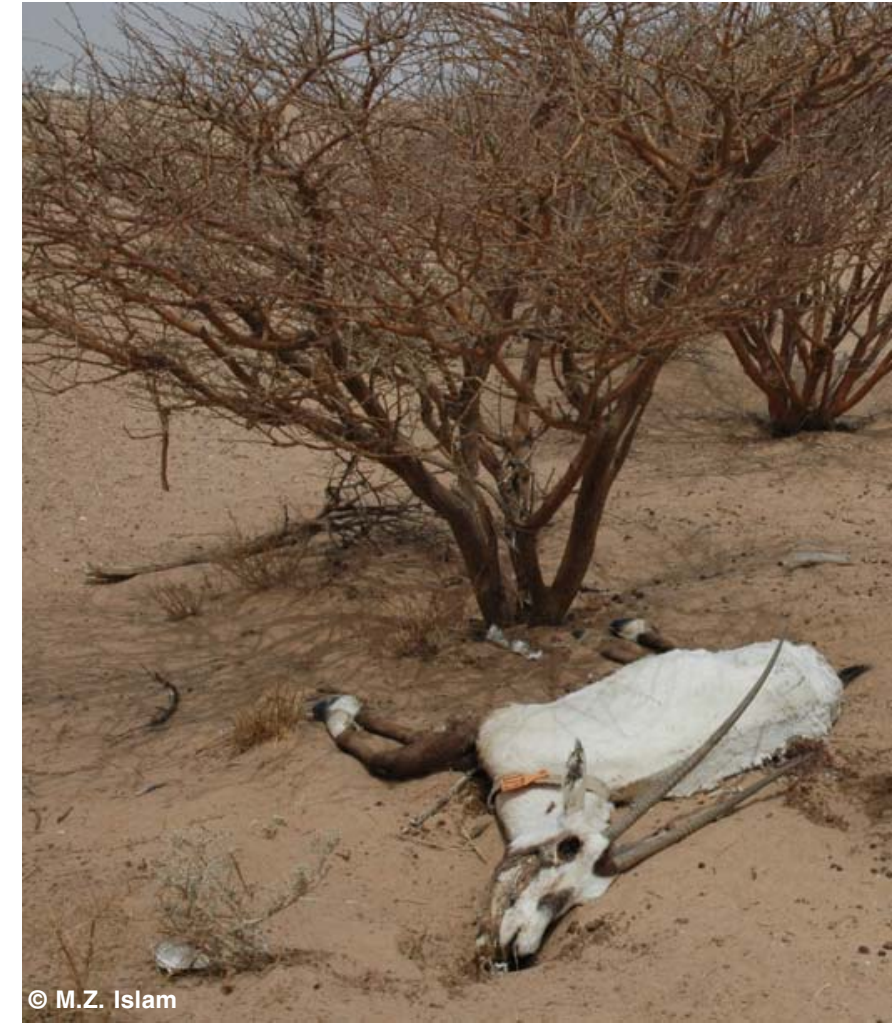

Image 4. Dead Arabian Oryx under a dry acacia tree.

by these carnivores has been initiated recently, but these carcasses were completely eaten or scavenged making it extremely difficult to identify the cause of mortality. But no animals that were investigated by a veterinarian had died due to any disease. Arabian Oryx is a free-ranging animal and moves long distances in search of food and the Mahazat fence prevents its movement especially during the stressful period when the food availability is extremely low and finally animals die near the fence.

\section{Distance of dead animals to the fence}

Most of the gazelle and oryx carcasses were recorded at an average distance of $3.075 \mathrm{~km}$ from the fence. The minimum distance where the dead animals were recorded was $5.62 \mathrm{~m}$ and the maximum distance was $15.53 \mathrm{~km}$.

Most of the carcasses were recorded near the northwestern, southern and southeastern parts of the reserve mostly under big green Acacia or Mearua trees, which offered thermal cover for ungulates at Mahazat during summer months: while in the northeastern part very few carcasses were recorded at sites where there was less vegetation (Image 1 \& Image 4).

Mortality of Arabian Oryx and Arabian Sand Gazelle were surveyed in Mahazat as-Sayd from 1989 to 2008 and it was found that mortality of these animals almost every year occurred during summer months when the rainfall is negligible (Figs. 1 \& 2). In contrast to mortality, no thermal stress was identified in 2006 and 2008. Deaths were due to starvation because of reduced availability, accessibility and quality of food plants in the area (Islam et al. 2007).

Rainfall has a strong influence on the presence or absence of annual plants, and is also the most important factor in production of grazing. Poor rainfall has had a major detrimental impact on forage in the reserve since eight years (Islam et al. 
2007). Sometimes, even if there is adequate rainfall, vegetation regeneration does not take place significantly to provide food to the whole population of oryx and gazelle which leads to mortalities of animals.

The composition of food plants consumed by grazers varies according to the season. In areas with sporadic unpredictable rains such as Mahazat as-Sayd, food composition is highly variable and is strongly correlated to rainfall (Ismail 2007). As in all dry areas, food consumed by oryx and gazelles contains a high percentage of cellulose and lignin (Anajariyya S. pers. comm. 2007).

The underground parts of arid region plants can be an important source of moisture for oryx, especially during a stressful period. However, in Mahazat as-Sayd very few plant species have a storage organ. Furthermore, the majority of these plants are annuals, which do not grow and survive without water. It was also recorded that in three major herbaceous plant species (Panicum turgidum, Stipagrostis plumosa and Lasiurius sp.) eaten by oryx the water content was decreasing over the years (Treydte et al. 2001).

Although it is known that different morphological and behavioral adaptations tend to separate sand gazelles and oryx with regard to feeding, thus reducing competition for food, both species were feeding on acacia pods when they were available. In May and June, at the start of summer, both species benefited a lot from this source of protein and water (Treydte et al. 2001). At that time the choice of browse was restricted to Acacia tortilis pods, and there was obviously competition between sand gazelles and oryx (Ostrowski \& Ismail 2000). Unlike the gazelles, oryx could still graze what was available on the ground (Seddon et al. 1999). Later in the season the acacia pods dropped onto the ground and still constituted a major source of food (although of poorer quality) for gazelles (Ismail 2006). By mid-July, the first dead gazelles were recorded, when browse was lacking. At that time oryx were grazing on some green vegetation (Treydte et al. 2001). Oryx eat young grass seed heads when available. During stressful periods, animals tend to eat a greater proportion of stalks to grass leaves than do other wild grazers. When grazing, sand gazelles feed mainly on grass seed heads and sometimes on leaves, but very few stalks are consumed (Islam et al. 2007). Early mortality among gazelles could be due to poor grazing available for this species, and complete lack of browse. Water content is supposed to be a major factor determining the acceptability of food by ungulates. Arabian Oryx have been observed in the wild to feed on very dry matter $(<20 \%$ moisture in Stipagrostis plumosa) (Treydte et al. 2001).

Observations on ungulate species agree that they are mixed feeders with the bulk of the diet as relatively coarse grass, augmented by forbs, mostly ephemerals (Newby 1985). Price (1987) says that the shrubs and tree browse are rarely taken and oryx takes newly flushed Acacia species foliage in the absence of green grazing. Grazing of oryx habitat depends on rainfall and animals move over great distances in response to rain. Ostrowski \& Ismail (2000) mention that the fence around Mahazat as-Sayd prevents natural movements of animals, and artificially concentrates the ungulate populations into possibly unfavourable habitat. The Sand Gazelle is a highly gregarious and migratory species, moving long distances in search of good quality pastures. Migratory movements of the sand gazelle in Arabia are legendary among nomadic bedouin, who relate tales of gazelle moving towards the lightning of thunderstorms in order to reach foraging grounds when ephemeral species sprout (Thesiger 1959). Raswan (1935) describes mass movements of sand gazelles away from areas of drought. Populations of goitered gazelles G. s. subgutturosa in Central Asia are also known to migrate over large distances, covering several hundred kilometres (Heptner et al. 1966). It is therefore likely that by preventing natural movements of sand gazelles, fencing may have "reinforced" the effects of drought conditions. It is important to keep in mind that Mahazat as-Sayd was not the typical habitat for the sand gazelle, and that reintroduction of this species in the area appears questionable with respect to its known past distribution. Ostrowski \& Ismail (2000) also mentioned that it is questionable whether the animals would find better habitats in the Nejd region without being fenced in. In the former Aden Protectorate, in April and May when conditions in the sands were heating up, small groups of oryx of 80 to 100 individuals tended to move from the sands to green patches on the gravel plains (jol) in the northeastern corner of the Protectorate (Grimwood 1962). However, should rain fall in the sands, or when oryx were disturbed on the jol, they then retreated back into the sands (Stewart 1963).

It is indeed clear that the fence does play a role in sand gazelle and oryx population dynamics, and that in the relatively small area of Mahazat as-Sayd, the restriction of movement can create a problem requiring a certain level of management.

\section{Management plan}

The ungulate populations in the Mahazat As-Sayd PA are valuable resources that could be put to good conservation (or other use) with careful planning.

A Management Plan for the ungulate populations in the Mahazat As-Sayd PA was developed in 2008 by ecologists, biologists, botanists, vets, sociologists and policy and decision makers to minimize periodic large-scale mortalities in the Reserve (Islam \& Knutson 2008).

In the plan, artificial provision of water and alfalfa at five different locations to animals in Mahazat since May 2008 was proposed and implemented that helped in minimizing the mortalities. It was observed that during the second week of September, gazelle, oryx and ostriches have started breeding though the condition in the reserve was not suitable as it is completely dry all over (Image 5). There is a possible danger that pregnant females might not come with the group to provision sites and if they don't get sufficient food and water they might die and there will be a great loss to the reserve.

To deal with this situation, it was recommended that as many oryx and sand gazelle may be removed from the PA as possible. There is currently not enough vegetation to support the population and additional deaths appear imminent unless preventative action is taken. Because translocation or other means of removal are not readily available, supplemental feeding and watering is deemed necessary to reduce the likelihood of mass mortalities.

Nonetheless, the removal of oryx and sand gazelle has to begin immediately by transferring supplemental feeding and water (currently going on in the PA) to the west enclosure sites to lure animals for passive capture. Since many of the animals are currently on the east side of the PA, it is expected that an enclosure may need to be constructed on that side to assist in the capture. If necessary, additional portable enclosures will be utilized throughout the reserve to ensure that a large percentage of the animals are removed from the PA.

Beside these, several research project proposals would be developed to investigate aspects such as vegetation and habitat, carrying capacity, Identification of potential PAs for 


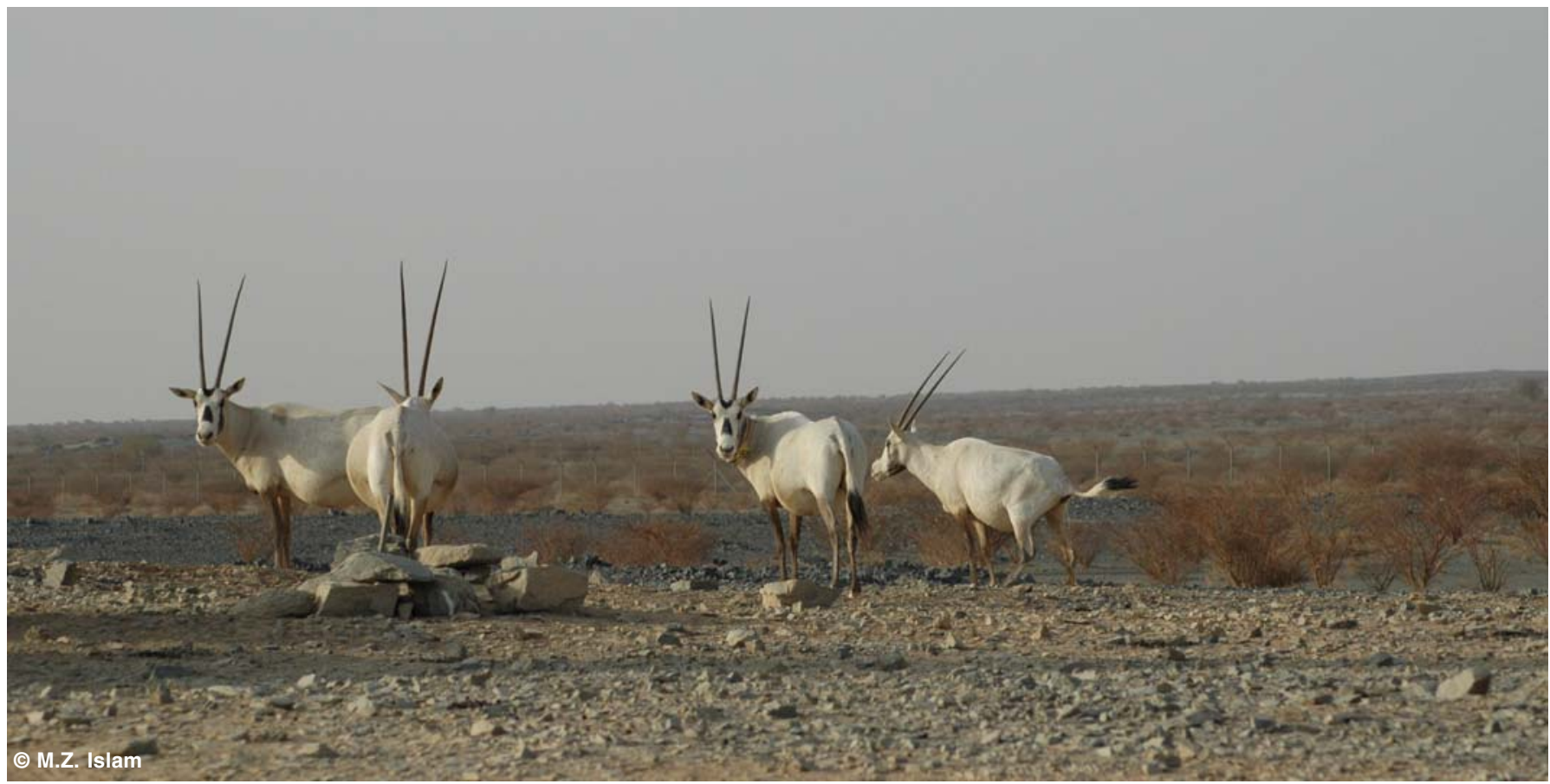

Image 5. Arabian Oryx near the camp waiting for water. Dry acacia plants can be seen in the background.

translocation of animals from Mahazat, and feeding ecology of gazelles and oryx.

\section{References}

Asmode, J.F. (1990). Mahazat as-Sayd Arabian Sand Gazelle Reintroduction Project 1990 Activity Report. NWRC Report, Taif. unpublished.

Asmode, J.F. (1991). Mahazat as-Sayd Arabian Oryx Reintroduction Project November 1988/July 1991. NWRC report, Taif. Unpublished.

Buckland, S.T., D.R. Anderson, K.P. Burman \& J.L. Laake (1993) Distance Sampling: Estimating Abundance of Biological Populations. Chapman and Hall, London.

Bothma, J. du P. (1996). Important ecological principles in Game Ranch Management. Bothma, J du P. \& J.L. van Schaik (eds.). Pretoria, pp.7-25.

Grimwood, I.R. (1962). Operation Oryx. Oryx 6: 308-334.

Haque, M.N. \& T. Smith (1993). Re-introduction of sand gazelle in Saudi Arabia. Abstract for the Sixth International Theriological Congress, Sydney.

Harrison, D.L. \& P.J.J. Bates (1991). The Mammals of Arabia. Harrison Zoological Museum, England, 354pp.

Heptner, V.G., A.A. Nasimovich \& A.G. Bannikov (1966). Mammals of the Soviet Union. 1988 edition. Amerind Publishing, New Delhi.

Islam, M.Z. \& C. Knutson (2008). A plan to reduce the risk of mass mortalities of reintroduced animals in the Mahazat as-Sayd Protected Area in Saudi Arabia. National Wildlife Research Center, Taif, Saudi Arabia.

Islam, M.Z., A. Boug, K. Ismail, P.M. Basheer, M.S. Shah, H. Subai, Musleh \& W. Rahman (2008). An evaluation of ungulates in the Mahazat as-Sayd Protected Area. NWRC Annual report.

Islam, M.Z., A. Boug, S. Anagariyah, K. Ismail, E.R. Robinson \& O.B. Mohammed (2007). Catastrophic die-off of reintroduced animals in Mahazat as-Sayd Protected Area in arid central Saudi Arabia. National Wildlife Research Center, King Khalid Wildlife Research Center and National Commission for Wildlife Conservation and Development, Saudi Arabia, 60pp.

Ismail, K. (2006). Report on ungulate and ostriches mortalities in Mahazat as-Sayd Protected Area during summer 2006. NWRC Annual Report, Taif, Saudi Arabia.
Magin, C. (1995). Ungulate Surveys in Mahazat as Sayd Reserve. NWRC unpublished report (May-October).

Mallon, D.P. (2008). Gazella subgutturosa. In: IUCN 2009. IUCN Red List of Threatened Species. Version 2009.2. $<$ www.iucnredlist.org>. Downloaded on 19 January 2010.

Newby, J.E. (1985). Large mammals, pp. 277-90. In: CloudsleyThompson, J.L. (ed.). Key Environments: Sahara Desert. Oxford: IUCN and Pergamon Press.

Ostrowski S. \& K. Ismail (2000). Report on ungulate mortality in Mahazat as-Sayd protected area during summer 2000. NWRC annual report 2000: 153-165. Unpublished report, NWRC, Taif, Saudi Arabia.

Ostrowski, S. \& K. Ismail (2000). Report on ungulate mortality in Mahazat As-Sayd Protected Area during summer 2000, pp. 153165. NWRC Annual Report, Saudi Arabia, 380pp.

Ostrowski, S. \& J.B. Williams (2006). Heterothermy of free-living Arabian sand gazelles (Gazella subgutturosa marica) in a desert environment. Journal of Experimental Biology 209: 1421-1429.

Philby, H.St.J.B. (1933). The Empty Quarter. Constable \& Co. Publishers, London, 576pp.

Price, M.R.S. (1987). Animal Re-introductions: the Arabian Oryx in Oman. Cambridge University Press, 291pp.

Raswan, C.R. (1935). The Black Tents of Arabia. Hutchinson, London, 220pp.

Roberts, T. J. (1977). The Mammals of Pakistan. Ernest Benn Limited, UK.,361pp.

Shah, M.S., A. Boug \& P. Cunningham (2008). Mortalities of Rheem Gazelle in Mahazat as-Sayd Protected Area. NWRC internal report, Taif, Saudi Arabia.

Seddon, P. (1999). Unpublished Report 1999, National Wildlife Research Center, Taif, Saudi Arabia.

Seddon, P.J., K. Ismail, M. Shobrak, S. Ostrowski \& C. Magin (2003). A comparison of derived population estimate, markresighting and distance sampling methods to determine the population size of a desert ungulate, the Arabian oryx. Oryx 37(3): 286-294.

Stewart, D.R.M. (1963). The Arabian Oryx (Oryx leucoryx Pallas) East African Wildlife Journal 103-117.

Thesiger, W. (1994). Arabian Sands. Motivate Publishing, Dubai, UAE, 306pp.

Thesiger, W. (1959). Arabian sands. Longmans, London, xvi+326pp. 
Treydte, A.C., J.B. Williams, E. Bedin, S. Ostrowski, P.J. Seddon, E.A. Marschall, T.A. Waite \& K. Ismail (2001). In search of the optimal management strategy of Arabian Oryx in Mahazat as-Sayd, Saudi Arabia. Animal Conservation 4(3): 239-249.
Author Details: M. ZAFAR-UL ISLAM is field biologist with strong interest in international wildlife conservation and had been associated with BirdLife International (UK), RSPB (UK), BNHS (India) and Aligarh Muslim University (India). His main research work is on ecology and biology of key species of birds and their habitat evaluation and niche modelling. Since April 2006, he is looking after the Research and Field Monitoring Department at the National Wildlife Research Center and handling the reintroduction programs of Houbara Bustard, Rednecked Ostrich and Arabian Oryx.

Ahmed Boug is General Director of National Wildlife Research Center and field biologist who studied the ecology and biology of Hamadrays Baboon in Saudi

Arabia. He has produced several papers in international journals on his research.

KHAIRI ISMAIL is field researcher working in Mahazat as-Sayd protected area in Saudi Arabia since last 20 years on Arabian Oryx, Gazelle and also monitoring Red-necked Ostrich. He has published several papers in international journals.

Author Contribution: Authors have been involved in collecting animal mortalities data in Mahazat mainly by Khairi and since 2006 Zafar also involved in the process mainly in the analysis of data. Authors have been reporting the issue to the policy and decision makers to implement the Strategic Plan to minimize animal mortalities in the Reserve.

Acknowledgements: We want to extend our thanks and gratitude to $\mathrm{HH}$ Prince Bandar bin Saud Bin Mohammed Al Saud (Secretary General, NCWCD) for his leadership, generosity and continuous support towards the research and conservation work by the NWRC in the Kingdom. We want to thank our former colleagues at NWRC: S. Ostrowsky, A. Treydte, M. Strauss for their contributions on drought related problems. All NWRC staffs are acknowledged for their help and M.S. Shah for providing the numbers of dead gazelles during 2008. We want to acknowledge Dr. Saud Anajariyya for reviewing the paper. 